\title{
Creating Eco-Innovations for Sustainable Entrepreneurship and Development within European Countries
}

\author{
Viktor Prokop ${ }^{1}$, Jan Stejskal ${ }^{1}$, Petr Hajek ${ }^{1}$ and Ondrej Kuba ${ }^{1}$
}

\begin{abstract}
There is no doubt that innovations represented key source of competitive advantage in the last years. Therefore, firms were forced to come up with new or significantly improved goods, services as well as organizational and marketing practices. However, countries, firms and policy makers are facing great environmental challenges for sustainable development and entrepreneurship, which create large demand for Eco-innovations with environmental benefits nowadays. For these reasons, we are analyzing different factors influencing creation of firms' Eco-innovations in the EU. To obtain an interpretable model of firms' Eco-innovations and their determinants, we use fuzzy rule-based classification models and latest available data form Community Innovation Survey 2012-2014 created by Eurostat. Our results show that firms' Eco-innovations are influenced by different factors according to the nature of innovation (product, process, organizational, marketing) in the EU. Public financial subsidies and firms' environment (e.g. existing environmental regulations, taxes, charges or fees, market demand, and costs of inputs) play key role in the process of creation Ecoinnovation with environmental benefits. These results show possible ways how support sustainable entrepreneurship and regional (national) development not only within analyzed countries. We provide initial analysis dealing with different kinds of Eco-innovations and its determinants that could help firms to develop and enhance their corporate innovation and environmental policies. These results could also inspire policy makers at different levels because we propose some practical implications.
\end{abstract}

Keywords: eco-innovations, sustainable development, environmental benefits, entrepreneurship

\section{Introduction}

Sustainable development is one of the most frequently discussed topics in many areas of human life. It concerns both social and economic topics as well as business. Discussions are still intensifying, thanks to current threats in different parts of the world, to diseases, war conflicts, or food or water supplies. Other pressing issues are global climate change, various threats to ecosystems, or significant over-consumption or sustainable energy production (Ajanovic, 2011).

These (often fatal) problems force a reaction to both the entrepreneur and the entire business sector. Over time, it has turned out that business and entrepreneurship must also address the issue of sustainability that it must successfully pass through the process of social and economic transformation. It has been shown that many of the opportunities lie outside the private sector, and that private and public sector cooperation is expected to address certain societal challenges.

One solution (found for this type of problem) is to ensure the sustainable production of such products that can dynamically address today's unnamed problems (Robèrt, 2002). It is mainly about the production of eco-innovations as a specific group of innovative 
products or innovative solutions, i.e. outputs of sustainable business or sustainable entrepreneurship.

The task of economic research is to analyze the current changes in the globalized economy, as well as the changes in the global challenges of sustainable development, and to define the principles on which fatal consequences can be avoided, but at the same time provide society with sufficient welfare. The subject of research must be the effective allocation of scarce resources, both in the public and private sectors, and in ensuring the continuous creation of innovations respecting the above-mentioned assumptions while respecting the principles of sustainable development (Stiglitz, 2002).

The remainder of this paper is structured as follows. In the next section, we present the theoretical background for sustainable entrepreneurship and eco-innovations. Section 3 provides the characteristics of the dataset and the research methodology. Section 4 presents the experimental results. In Section 5, we discuss the results that were obtained and concluded with the paper for suggestions for future research.

\section{Theoretical Background}

As demonstrated by many examples, Hall, Daneke \& Lenox (2010), despite various discussions about the validity of the concept of "sustainable development", is a principled approach that is applied in various fields, including academic and managerial. Sustainability is a concept that is accented today in various public policies (e.g. industrial policy), but also in corporate strategies. Individual companies and companies have specialized staff or departments dealing with the sustainability of their own production, social responsibility, etc. Interestingly, every economic subject under the term "sustainability" represents its own concept, sometimes focused on social aspects, sometimes more on economy, performance waste reduction, etc. (Elkington, 1998).

Various studies show that the concept and approach to sustainability are mainly due to the company's maturity and openness. Companies cooperating with foreign countries encounter the issue and can expect a far more sophisticated and smarter use of the sustainability concept. Ambec \& Lanoie (2008) present examples of companies that have been able to gain additional revenue by applying the concept of sustainable development. Conversely, companies closed or oriented towards CEE markets perceive sustainability in the context of waste management or the exchange of learning production factors as more environmentally friendly. They cannot take advantage of, for example, product differentiation, access to certain specific (and dynamically developing) markets, as well as green product or technology sales, lower input costs, or optimization of labor needs.

Some authors in this context recall the issue of market failure and the role of the state in this issue. In the area of sustainable development, the private sector (entrepreneurs) must be seen as an important partner in finding ways and new approaches. The net market mechanism tends to be unsustainable. Thus, there is a market failure that the public sector (stat) must address and prevent. It is the support of entrepreneurs that accentuates sustainable development, ecology, eco-innovation, etc. to help address the consequences of market failure. Entrepreneurship was one of the ways in which market failure was addressed by A. C. Pigou in the early 20th century and subsequently by R. H. Coase (Coase, 1974). These concepts were followed by a series of scholars, and their work is 
precisely reviewed in Hall, Daneke \& Lenox (2010).

In the course of the 20th century, various studies were published that discussed the role of the state or the public sector in the economy. Excessive state intervention (consisting in providing financial support or strict regulatory measures) has proven counterproductive or very inefficient. In addition, some of the public interventions have disrupted pension equality (sometimes equitable distribution of economic growth). Some authors point to the possibility of depleting scarce resources (mineral resources) and the need for technological advances to replace depleted resources. The uneven pace of technological innovation and resource depletion may in the future cause difficulties for industry-oriented and resource-based economies and productions. Balakrishnan et al. (2003) even notes that sustainability is not in line with the traditional capitalist orientation of market economies. To ensure sustainability, it will be necessary to reduce the pace of economic growth, which is unacceptable at the moment. Thus, the so-called heuristic problem (Rennings, 2000) has become sustainable.

Innovation is one of the solutions to the situation. Some scholars are skeptical about this, but the situation in a globalized economy shows that international organizations believe that entrepreneurs are able to recognize new challenges and are able to reformulate their business plans and activities to make them sustainable. The target is, therefore, that businesses start producing sustainable eco-innovations within their normal innovative practices. The attribute of this sustainability will therefore be to reduce at least partial environmental burdens. Thus, eco-innovation will be an innovation that introduces new products, processes or processes that contribute to reducing the environmental burden of the environment or to ecologically specified sustainability goals (Klemmer et al., 1999). Eco-innovations are products of companies or other organizations that are commercialized by innovation activities at different levels.

There are a number of studies dealing with eco-innovation. These usually belong to socalled innovation economics. Here, innovations are seen as outputs that cause spill-over effects in the phase of innovation, but also its diffusion. This is usually due to lower production costs due to lower market competition. This paradox is sometimes referred to as a double externality problem (Rennings, 2000). This problem reduces the willingness of companies to invest in eco-innovation. It is therefore essential that public policies towards sustainability and affecting the production of eco-innovation are sufficiently coordinated and based on the same financial assumptions. Innovation policy in this area can reduce production costs, but also various other types of costs such as social costs in marketing eco-innovations.

The European Union's sustainability policy is a coordinated policy and its outputs can therefore be analyzed. There are only a few studies that analyze the effectiveness of this policy and the ability of European companies to produce eco-innovation. Ghisetti, Marzucchi \& Montresor (2015) in their study explored open innovations in an environmental context. They used CIS data from Eurostat (2006-2008) and found that internal innovation capabilities and knowledge-based socialization mechanisms reduce the impact of knowledge gained through deep external interactions. Horbach (2014) used the same data and examined the determinants of eco-innovation from a European-wide perspective. He found that environmental subsidies are more important for Eastern European countries, pointing to the lower financial performance of their respective 
countries. Moreover, Eastern European countries rely more heavily on competitors and external research and development as information sources indicating technology transfer from west to east. Scholars Marin, Marzucchi \& Zoboli (2015) then examined SMEs and barriers to eco-innovation in the EU. They found that barriers to eco-innovation could then become a decisive factor in preventing or stimulating EU strategies, implementing policies and environmental strategies. They also dealt with selected clusters and innovation production in the context of public policies.

It is thus clear that current research does not work sufficiently with data to analyze ecoinnovations and their barriers through economic analysis. Therefore, the goal of this paper is to fill the gap and provide initial analyses that obtain an interpretable models of firms' Eco-innovations and their determinants in selected European countries (Bulgaria, Croatia, Cyprus, Estonia, Greece, and Hungary). Similar innovation policies have been identified that are applied in these countries and therefore we could provide benchmarks for less efficient firms and countries and identify factors driving enterprise's decisions to introduce innovations with environmental benefits. Moreover, it could help firms to develop and enhance their corporate innovation and environmental policies and inspire policy makers at different levels.

\section{Data and Methodology}

When selecting above mentioned countries, the availability of data had to be taken into account. We are using the principal instrument of the EU monitoring advancement in the field of innovation - the CIS: Community Innovation Survey 20122014 (the latest available data) that uses harmonized questionnaire created for all EU Member States by Eurostat and combines stratified random sampling with exhaustive surveys addressing firms directly (Prokop et al., 2019). In total, we analyze 3,631 firms from six countries (Bulgaria, Croatia, Cyprus, Estonia, Greece, and Hungary). To make it possible to generalize the results on the whole group of countries and to provide benchmarks for other firms and countries the analyses are not done for each country separately but the merged dataset of all selected countries together is used instead. While firms are not operating in isolation (see Fig. 1), we analyze not only influence of factors driving enterprise's decisions to introduce innovations with environmental benefits but also influence of other control variables - factors from firms' environment. These control variables are: (i) market orientation that could be seen as the crucial framework to reach new customers and suppliers, to improve the sustainability of competitive advantage and to raise long-time profit and innovations (Ho et al., 2018); (ii) public financial support for innovation which for example spur innovation with tailor-made support in close collaboration with the private sector (Grotenbreg \& van Buuren, 2018); (iii) educated human resources that contribute to expanding firms' absorption capacity and to build valuable capabilities that lead to innovations and provide competitive advantages over other organizations (De Massis et al., 2018); (iv) firm size ${ }^{1}$ represented by firms' turnover that has (together with governmental support) moderating role in

1 According to Lee \& Xia (2006) firm size could be defined as organization's resources, turnover, or workforce size. In this paper, we consider firms' turnover as a proxy for firm size. 
innovation performance in an emerging market environment and is commonly considered a control variable in innovative processes (Jugend et al., 2018); (v) firms' innovation expenditures which results in increased internal knowledge spillovers and sustainable performance (Hajek \& Stejskal, 2018; Prokop et al., 2018).

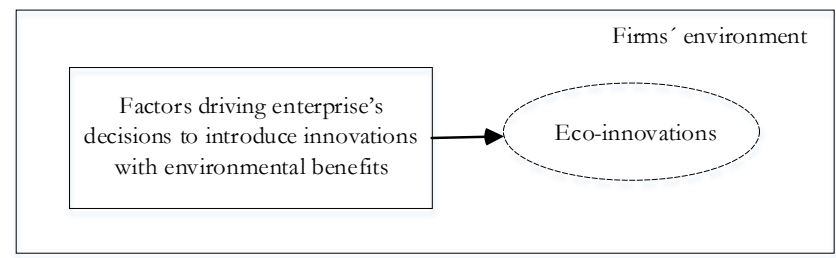

\section{Figure 1: Proposed research framework}

All selected output variables representing different firms' eco-innovations as well as input variables (determinants) are shown in Table 1.

Table 1: Description of selected variables

\begin{tabular}{|c|c|c|}
\hline \multicolumn{3}{|l|}{ Outputs } \\
\hline \multirow[t]{4}{*}{ Eco-Innovations } & ECOPRD & Product (goods or services) innovations \\
\hline & ECOPRC & Process innovations \\
\hline & ECORG & Organizational innovations \\
\hline & ECOMKT & Marketing innovations \\
\hline \multicolumn{3}{|l|}{ Inputs } \\
\hline \multirow{9}{*}{$\begin{array}{l}\text { Factors driving } \quad \text { enterprise's } \\
\text { decisions to introduce innovations } \\
\text { with environmental benefits }\end{array}$} & ENEREG & Existing environmental regulations \\
\hline & ENETX & Existing environmental taxes, charges or fees \\
\hline & ENREGF & $\begin{array}{l}\text { Environmental regulations or taxes expected in the } \\
\text { future }\end{array}$ \\
\hline & ENGRA & $\begin{array}{l}\text { Government grants, subsidies or other financial } \\
\text { incentives for environmental innovations }\end{array}$ \\
\hline & ENDEM & $\begin{array}{lcccc}\begin{array}{l}\text { Current or expected market } \\
\text { environmental innovations }\end{array} & & & \text { for } \\
\end{array}$ \\
\hline & ENREP & Improving enterprise's reputation \\
\hline & ENAGR & $\begin{array}{l}\text { Voluntary actions or initiatives for environmental } \\
\text { good practice within firm sector }\end{array}$ \\
\hline & ENCOST & High cost of energy, water or materials \\
\hline & ENREQU & $\begin{array}{l}\text { Need to meet requirements for public procurement } \\
\text { contracts }\end{array}$ \\
\hline \multirow{6}{*}{$\begin{array}{l}\text { Market orientation } \\
\begin{array}{l}\text { Public financial support for } \\
\text { innovation activities }\end{array}\end{array}$} & LARMAR & Largest geographical markets in terms of turnover \\
\hline & FUNLOC & From local or regional authorities \\
\hline & FUNGMT & $\begin{array}{l}\text { From Central government (including central } \\
\text { government agencies or ministries) }\end{array}$ \\
\hline & FUNEU & From The European Union (EU) \\
\hline & FUNRTD & $\begin{array}{l}\text { From the EU 7th Framework Programme for } \\
\text { Research and Technical Development or the } \\
\text { Horizon 2020 Programme for Research and } \\
\text { Innovation }\end{array}$ \\
\hline & FUN_ALL & From several budgets \\
\hline Human resources & EMPUD & Enterprise's employees in 2014 with tertiary degree \\
\hline Firm size & TURN14 & Enterprise's total turnover for 2014 \\
\hline Innovation expenditures & RALLX_RAT & Total firms' expenditures on the innovation activities \\
\hline
\end{tabular}


To obtain an interpretable base of rules showing the impact of the considered determinants on eco-innovations, we selected to use the FURIA algorithm (Huhn, 2009), the state-of-the-art fuzzy rule-based system that extracts rules from the data in an inductive manner. To be more precise, FURIA represents an extension of a well-known rule induction algorithm RIPPER. The FURIA algorithm works as follows. In the first step, the antecedents (conditions) of rules are gradually added using modified RIPPER in order to obtain the most accurate rules. In the second step, the set of rules is pruned to minimize the description length in order to achieve more interpretable set of rules. To incorporate the fuzzy sets into the RIPPER algorithm, the antecedents are fuzzified and those with the highest rule purity are retained. Specifically, crisp intervals in RIPPER are replaced with trapezoidal fuzzy sets (membership functions). As a result, more uncertainty in the data can be taken into consideration and better comprehensibility of the model can be achieved. In fact, the use of linguistic terms such as low or high, representing the fuzzy sets, is preferable for the human decision makers.

\section{Results and Discussion}

To avoid overfitting of the classification models, 10-fold cross-validation was used to divide the datasets into ten sets of training and testing data. Thus, the model was trained on $90 \%$ of the data and tested on the remaining $10 \%$. This procedure was repeated ten times to obtain unbiased estimates. To evaluate the quality of the classification models, classification accuracy was applied and we report average accuracy obtained for the ten testing datasets along with standard deviations. Thus, accuracy of the model together with its stability can be evaluated. In addition to accuracy, interpretability of fuzzy rule-based models should be evaluated. In this study, we evaluated both the number of antecedents (conditions in the rules) and the size of rule base (number of rules). It should also be noted that trade-off between accuracy and interpretability have been observed in earlier research and it is the user that should provide his/her preferences (Hajek, 2018). We decided to prefer the interpretability of the models at the granularity level and, therefore the number of linguistic terms was fixed to five for all models. In other words, only five intervals were used that represent the following linguistic terms: very low, low, medium, high and very high.

The results of the experiments are presented in Table 2. The average accuracy of all classification models on testing (unseen) data (companies) ranged from 60.64 to $84.91 \%$. This finding suggests that Model 2 represents the most complex classification problem, while Model 4 provides a highly accurate model with a low standard deviation. On the one hand, as obvious from the interpretability measures, high accuracy was achieved at the cost of more complex models, as indicated by a higher number of antecedents (conditions) in the rules. On the other hand, regarding rule-base interpretability, Model 4 achieved the high classification accuracy using only 2.64 rules on average. Overall, all the models provided a good trade-off between accuracy and interpretability. 
Table 2: Accuracy obtained by FURIA on four eco-innovation models

\begin{tabular}{|l|c|c|c|c|}
\hline & Model 1 & Model 2 & Model 3 & Model 4 \\
\hline Accuracy [\%] & 64.20 & 60.64 & 69.82 & 84.91 \\
\hline St. dev. [\%] & 3.63 & 2.25 & 0.94 & 0.11 \\
\hline \# Antecedents & 1.71 & 1.79 & 4.50 & 8.10 \\
\hline \# Rules & 3.40 & 3.40 & 21.1 & 2.64 \\
\hline
\end{tabular}

For each model, the specific set of rules was obtained. Due to the space limitation, here we show a representative example of the rules. More precisely, the rules with the highest grades of certainty (top 5 rules) for classes 0 (non-innovative company) and 1 (innovative company) were as follows:

\section{Model 1:}

R1: (rallx_rat is very low) $=>$ ecoprd $=0$

R2: (endem $<=$ low) $=>$ ecoprd $=0$

R3: (rallx_rat $>=$ very low) and (endem $>=$ high) $=>$ ecoprd $=1$

R4: (rallx_rat $>=$ very low) and (endem $>=$ medium) and (empud $>=$ very high) $=>$ ecoprd $=1$

R5: (rallx_rat $>=$ low) and (empud $>=$ high) $=>$ ecoprd $=1$

\section{Model 2:}

R1: (rallx_rat $<=$ very low) and (fun_all $<=$ very low) $=>$ ecoprc $=0$

R2: (enagr $<=$ low) and (enereg $<=$ low) $=>$ ecoprc $=0$

R3: (enagr $<=$ medium) and (turn14 $<=$ medium) and (fungmt $<=$ very low) $=>$ ecoprc $=0$

R4: (rallx_rat $>=$ very low) and (enagr $>=$ high $)=>$ ecoprc $=1$

R5: (rallx_rat $>=$ very low) and (turn $14>=$ high) $=>$ ecoprc $=1$

\section{Model 3:}

R1: (enagr $<=$ low) and (enetx $<=$ low) and (endem $>=$ low) and (empud $<=$ very high) and (rallx_rat $>=$ very low) and (turn $14>=$ high) $=>$ ecorg $=0$

R2: (enagr $<=$ low) and (empud $<=$ very high) and (rallx_rat $>=$ very low) and (enetx $<=$ very low) and (turn14 $<=$ medium) and (enrequ $<=$ very low) and (larmar $<=$ high) $=>\operatorname{ecorg}=0$

R3: (enagr $<=$ low) and (endem $>=$ low) and (enrequ $<=$ medium) and (engra $<=$ low) and (larmar $>=$ medium) and (enregf $>=$ medium) and (enagr $>=$ low) and (rallx_rat $>=$ low) $=>$ ecorg $=0$

R4: (enagr $>=$ high) and (enrep $>=$ high) and (enetx $>=$ low) and (enereg $<=$ medium) and (funeu $<=$ very low) $=>$ ecorg $=1$

R5: (enagr $>=$ high) and (enrep $>=$ high) and (empud $>=$ very high) and (enetx $>=$ medium) and (fun_all $>=$ low) $=>$ ecorg $=1$

\section{Model 4:}

R1: (enrequ $<=$ low) and (enrep $<=$ very low) and (larmar $>=$ medium) $=>$ ecomkt $=0$

R2: (enrequ $<=$ very low) and (turn14 $>=$ medium) and (empud $<=$ very high) and (turn14 $<=$ very high) and (enregf $<=$ medium) $=>$ ecomkt $=0$

R3: (enrequ $<=$ low) and (turn $14>=$ low) $=>$ ecomkt $=0$

R4: (endem $>=$ low) and (rallx_rat $>=$ low) $=>$ ecomkt $=1$

R5: (enrequ $>=$ very low) $=>$ ecomkt $=1$ 
Several interesting findings can be deduced from this sample of rules. For product ecoinnovations (Model 1), firms' expenditures on the innovation activities (rallx_rat) are necessary condition but it must be accompanied with high or medium current or expected market demand for environmental innovations (endem) together with very high number of firm employees with tertiary degree (empud). This is clear because firms' educated workforce in combination with high innovation expenditures including (i) expenditures on internal and external R\&D; (ii) acquisition of machinery, equipment, software and buildings; (iii) acquisition of existing knowledge from other enterprises or organisations; (iv) all other innovation activities including design, training, marketing, and other relevant activities lead to creation of firms' innovation environment enabling emergence of positive externalities (e.g. knowledge spillovers). These results are consistent for example with Leten et al. (2014) which showed that highly educated workers gave a positive contribution on patents produced by companies in Italy. Sharma et al. (2016) state that firms' $R \& D$ is an important dynamic capability and driver of product innovation and therefore innovation expenditures have a positive effect on product innovation and marketing performance. Moreover, current or expected market demand for environmental innovations support creation of firms' positive expectations that are generally connected with growing expenditures which lead to growing GDP and employment.

Akcigit \& Kerr (2018) state that there is a little understanding about the firms' innovation and growth patterns of different-sized firms and their contributions to macroeconomic growth. However, we show that in case of process eco-innovations, ecoinnovative companies must have either high turnover (firm size) or high voluntary actions or initiatives for environmental good practice within firm sector (enagr). Generally, larger firms have capacity and resources to invest in R\&D and innovation. Therefore high turnover allows these firms to increase their spending and to take a higher risks, which are associated with different types of innovation. On the other hand, small and medium-sized enterprises (SMEs) find such investments harder to make and therefore fosters collaboration and cooperation among employees, and requires less effort to coordinate them (Leal-Rodríguez et al., 2015).

For organizational and marketing eco-innovations, there are specific rules. Organizational and marketing innovations, in general, are relatively unexplored, even though the extensive research on the innovation and its determinants. Previous studies have mainly focused on technological innovations despite the fact that for example organizational innovation can act as the prerequisite for and facilitator of the efficient use of other (technological) innovation (Azar \& Ciabuschi, 2017). It was also noted that the most value-added components of any technology value chain, which also yield the highest profit margins, are not only $R \& D$ but also marketing innovations (Tsai \& Eisingerich, 2010). In the case of organizational eco-innovations we show that there must be high voluntary actions or initiatives for environmental good practice within firm sector (enarg) and improving enterprise's reputation (enrep) as a driving factors of firms' decisions to introduce innovations with environmental benefits. Simultaneously, existing environmental taxes, charges or fees (enetx) must be at least low. On the other hand, marketing eco-innovations were achieved through at least low current or expected market demand for environmental innovations (endem) and firms' expenditures on the 
innovation activities (rallx_rat) or need to meet requirements for public procurement contracts (enrequ). It is clear that low market demand and low firms' R\&D expenditures must be supplemented by increasing marketing innovations to find potentially new markets and customers.

\section{Conclusions}

Similarly to innovations that are seen as drivers of firms' and countries' growth, eco-innovations have gained in importance, even though it is still a new area of research. However, it is an area of increasing concern for firms, scholars (academics) and policy makers (Díaz-García et al., 2015) due to its indisputable contribution to sustainable entrepreneurship and development. Therefore, we analysed factors driving enterprise's decisions to introduce innovations with environmental benefits as well as other factors operating within firms' innovation environments that significantly influence the successful implementation of various types of eco-innovations within six European countries (Bulgaria, Croatia, Cyprus, Estonia, Greece, and Hungary). Our analyses obtained specific set of rules providing several interesting findings. On the basis of these findings we can propose some practical implications that can help firms in their ecoinnovation activities. While (product) innovations lead to higher costs (Sharma et al., 2016) as well as higher risks and management challenges, there is a need to support creation of market and governmental demand for environmental innovations (specifically in the case of product eco-innovations). It positively influences firms' expectations that lead to increase in firms' expenditures on the innovation activities (including e.g. internal and external research) which in turn contribute to the emergence of mutual synergies between the different actors in these processes and to creation of spillovers and innovations. We also propose workforce education and firms' cooperation with universities (knowledge generators) because gaining, creating and disseminating of knowledge seems to be crucial in the era of the knowledge economy. Meissner \& Shmatko (2017) state that universities are associated with the role of generators of knowledge who meet the needs of the knowledge society and serve as a source of national welfare in economic and social terms. Therefore, this kind of cooperation could help firms to expand their absorptive capacity and to meet the market needs. Next, we propose governmental support (e.g. public subsidies, tax benefits, consulting services, etc.) for firms financing their eco-innovations. Finally, we show that firm size matter in the process of eco-innovation creation therefore public policies must be set up to support the different needs of small, medium and large enterprises. As a possible limitation of this study we can see a small sample of countries and the absence of large economies. Therefore, for the future research, we plan to focus on larger economies and to analyse conditions of eco-innovation creation in each country separately.

\section{Acknowledgement}

This paper was supported by the Student Grant Competition (grant no. 18) of University of Pardubice in 2019. 


\section{References}

Ajanovic, A. (2011). Biofuels versus food production: Does biofuels production increase food prices?. Energy, 36(4), 2070-2076.

Akcigit, U., \& Kerr, W. R. (2018). Growth through heterogeneous innovations. Journal of Political Economy, 126(4), 1374-1443.

Azar, G., \& Ciabuschi, F. (2017). Organizational innovation, technological innovation, and export performance: The effects of innovation radicalness and extensiveness. International Business Review, 26(2), 324-336.

Balakrishnan, U., Duvall, T., \& Primeaux, P. (2003). Rewriting the bases of capitalism: reflexive modernity and ecological sustainability as the foundations of a new normative framework. Journal of Business Ethics, 47(4), 299-314.

Coase, R. H. (1974). The lighthouse in economics. The journal of law and economics, 17(2), 357-376.

De Massis, A., Audretsch, D., Uhlaner, L., \& Kammerlander, N. (2018). Innovation with Limited Resources: Management Lessons from the G erman M ittelstand. Journal of Product Innovation Management, 35(1), 125-146.

Díaz-García, C., González-Moreno, Á., \& Sáez-Martínez, F. J. (2015). Eco-innovation: insights from a literature review. Innovation, 17(1), 6-23.

Elkington, J. (1998). Cannibals with forks: The triple bottom line of sustainability. Gabriola Island: New Society Publishers.

Ghisetti, C., Marzucchi, A., \& Montresor, S. (2015). The open eco-innovation mode. An empirical investigation of eleven European countries. Research Policy, 44(5), 1080-1093.

Grotenbreg, S., \& van Buuren, A. (2018). Realizing innovative public waterworks: Aligning administrative capacities in collaborative innovation processes. Journal of Cleaner Production, 171, 45-55.

Hajek, P. (2018). Predicting corporate investment/non-investment grade by using interval-valued fuzzy rulebased systems - A cross-region analysis. Applied Soft Computing, 62, 73-85.

Hajek, P., \& Stejskal, J. (2018). R\&D cooperation and knowledge spillover effects for sustainable business innovation in the chemical industry. Sustainability, 10(4), 1064.

Hall, J. K., Daneke, G. A., \& Lenox, M. J. (2010). Sustainable development and entrepreneurship: Past contributions and future directions. Journal of Business Venturing, 25(5), 439-448.

Hemmelskamp, J., \& Jörg, S. (1999). Innovationswirkungen der Umweltpolitik im Windenergiebereich. Innovationen und Umwelt. Analytica-Verlag, Berlin, 81-112.

Ho, K. L. P., Nguyen, C. N., Adhikari, R., Miles, M. P., \& Bonney, L. (2018). Exploring market orientation, innovation, and financial performance in agricultural value chains in emerging economies. Journal of Innovation \& Knowledge, 3(3), 154-163.

Horbach, J. (2014). Determinants of Eco-innovation from a European-wide Perspective-an Analysis based on the Community Innovation Survey (CIS). SEEDS Working Paper, 7, 2014.

Huhn, J., Hullermeier, E. (2009). FURIA: An algorithm for unordered fuzzy rule induction. Data Mining and Knowledge Discovery, 19(3), 293-319.

Jugend, D., Jabbour, C. J. C., Scaliza, J. A. A., Rocha, R. S., Junior, J. A. G., Latan, H., \& Salgado, M. H. (2018). Relationships among open innovation, innovative performance, government support and firm size: Comparing Brazilian firms embracing different levels of radicalism in innovation. Technovation, 74, 54-65.

Leal-Rodríguez, A. L., Eldridge, S., Roldán, J. L., Leal-Millán, A. G., \& Ortega-Gutiérrez, J. (2015). Organizational unlearning, innovation outcomes, and performance: The moderating effect of firm size. Journal of Business Research, 68(4), 803-809.

Lee, G., \& Xia, W. (2006). Organizational size and IT innovation adoption: A meta-analysis. Information \& Management, 43(8), 975-985.

Leten, B., Landoni, P., \& Van Looy, B. (2014). Science or graduates: How do firms benefit from the proximity of universities?. Research Policy, 43(8), 1398-1412.

Marin, G., Marzucchi, A., \& Zoboli, R. (2015). SMEs and barriers to Eco-innovation in the EU: exploring different firm profiles. Journal of Evolutionary Economics, 25(3), 671-705.

Meissner, D., \& Shmatko, N. (2017). "Keep open”: the potential of gatekeepers for the aligning universities to the new Knowledge Triangle. Technological Forecasting and Social Change, 123, 191-198. 
Prokop, V., Stejskal, J., \& Hajek, P. (2018). The Influence of Financial Sourcing and Collaboration on Innovative Company Performance: A Comparison of Czech, Slovak, Estonian, Lithuanian, Romanian, Croatian, Slovenian, and Hungarian Case Studies. In Knowledge Spillovers in Regional Innovation Systems, 219-252.

Prokop, V., Stejskal, J., \& Hudec, O. (2019). Collaboration for innovation in small CEE countries. E+ M Ekonomie a Management, 22(1), 130-144.

Rennings, K. (2000). Redefining innovation-eco-innovation research and the contribution from ecological economics. Ecological economics, 32(2), 319-332.

Robèrt, K. H., Schmidt-Bleek, B., De Larderel, J. A., Basile, G., Jansen, J. L., Kuehr, R., ... \& Wackernagel, M. (2002). Strategic sustainable development-selection, design and synergies of applied tools. Journal of Cleaner production, 10(3), 197-214.

Sharma, P., Davcik, N. S., \& Pillai, K. G. (2016). Product innovation as a mediator in the impact of R\&D expenditure and brand equity on marketing performance. Journal of Business Research, 69(12), 56625669.

Stefan, A., \& Paul, L. (2008). Does it pay to be green? A systematic overview. Academy of Management Perspectives, 22(4), 45-62.

Stiglitz, J. E. (2002). Towards a new paradigm for development: strategies, policies and processes. Columbia: Columbia Academic Commons.

Tsai, H., Eisingerich, A. B. (2010). Internationalization strategies of emerging markets firms. California Management Review, 53(1), 114-135. 